\title{
EFFECTS OF DISTRACTION TYPE, DRIVER AGE, AND ROADWAY ENVIRONMENT ON REACTION TIMES - AN ANAL YSIS USING SHRP-2 NDS DATA
}

\author{
Laura Higgins, Raul Avelar, Susan Chrysler \\ Texas A\&M Transportation Institute \\ College Station, Texas, U.S.A. \\ Email: 1-higgins@tti.tamu.edu
}

\begin{abstract}
Summary: Effects of different types of cell phone use were examined through an analysis of selected data from the SHRP2 Naturalistic Driving Study (NDS). Driving events involving lead-vehicle or approaching-vehicle incidents were analyzed to compare driver reaction times and crash probability across driver distraction type, driver age, and roadway environment. The analysis found that the median reaction time was $40.5 \%$ higher among drivers engaged in a visualmanual task such as texting, and crash risk for those drivers was 4.66 times higher compared to drivers who were undistracted. Median reaction times in urban environments were longer than those in freeway environments. Drivers aged 1619 exhibited faster reaction times then older drivers, but higher crash risk.
\end{abstract}

\section{INTRODUCTION}

The increased crash risk posed by driver distraction has been examined by numerous studies over the past two decades. Analysis of driving data from the 100-Car Naturalistic Driving Study in the early 2000's found that drivers who were engaged in secondary tasks had a crash and near-crash risk three times as high as those who were not (Klauer, Dingus, Neale, Sudweeks, Ramsey, 2006). A recent analysis by Dingus et al. (2016), using the SHRP2 dataset, found that visualmanual tasks such dialing or texting on a cell phone increased the odds of being involved in a crash by 16- and 6-fold respectively. An observational study of 2229 crashes involving teen drivers over the years from 2007 to 2015 found increases in the proportions of rear-end crashes and of visually-distracted drivers over that time period. The study also found increases from 2007 to 2015 in average driver reaction times (from 2.0 to 2.7 seconds) and in the percentage of rear-end crashes in which drivers did not react prior to the crash (from 12.5\% to 25\%) (Carney, McGehee, Harland, Weiss, \& Raby, 2016).

A meta-analysis of 33 studies examining the effects of cell phone use on driver performance found an average increase of 0.25 seconds in driver reaction times when using either a hand-held or a hands-free cell phone (Caird, Willness, Steel, and Scalfia, 2008). Another meta-analysis of 28 texting-and-driving studies found varying increases in reaction time associated with writing and/or reading text messages while driving (Caird, Johnston, Willness, Ashbridge, and Steel, 2014). In 2011, a test-track texting and driving study (Cooper, Yager, and Chrysler, 2011) estimated a doubling of reaction time for drivers writing or reading text on a cell phone. One study of hands-free cell phone use indicated similar increases in reaction time for both younger (18-25) and older (65-74) drivers; older drivers displayed slower overall reaction times than younger drivers during both distracted and undistracted driving (Strayer and Drew, 2004).

Some driver distraction studies have indicated that the roadway environment can influence drivers' decisions to engage in secondary tasks (Funkhouser and Sayer, 2012; Tivesten and 
Dozza, 2014; Tivesten and Dozza, 2015); however, these studies do not specifically address the effects of the roadway environment on other performance measures such as reaction times. This analysis of naturalistic driving data from the Strategic Highway Research Program's Naturalistic Driving Study (SHRP2 NDS) was conducted to examine the relative effects of secondary task distraction, driver age, and roadway environment on reaction time and crash risk. A secondary goal of the analysis was to explore the utility of the pre-coded NDS data for driver performance research.

\section{METHODOLOGY}

This analysis used pre-reduced data from SHRP2 NDS to conduct a statistical evaluation of driver reaction times connected with lead-vehicle or approaching-vehicle incidents, including crashes and near-crashes, for both distracted and non-distracted drivers. The NDS data include numerous variables describing each vehicle event, such as driver characteristics, vehicle characteristics, trip characteristics, and event characteristics. The data were created by manual review of forward scene and in-cab video conducted by trained data reductionists at Virginia Tech Transportation Institute (VTTI), or were populated from map data and demographic information provided by the study's participants. The current team of researchers selected 249 events from 179 drivers, including 22 crashes, involving driver reaction times to precipitating events. Selection criteria included the following:

- Events involving lead vehicle or approaching vehicle conflicts, including rear-end, headon, or sideswipe conflicts, or road departures.

- Events that included a recorded driver reaction time start to a precipitating event.

- Events in which the driver had at least one hand on the steering wheel.

- Roadway environments including residential, urban, interstate/bypass/divided highway with no traffic signals, or bypass/divided highway with traffic signals.

- Events in which the subject driver was at fault (in case of a crash or near-crash).

- Events that took place in daylight, with no adverse weather conditions.

- Events in which drivers were either not engaged in a secondary task, or were using or holding cell phones (no other distraction types were included).

The research team created three cell phone use categories from several sub-categories reported in the NDS data: none/baseline (no secondary task), manual-cognitive (e.g., cell phone holding, talking, and listening), and visual-manual (e.g., texting and browsing). Drivers distracted by visual-manual or manual-cognitive tasks were expected to exhibit longer reaction times to events compared to undistracted drivers. Event locations included urban, residential, and freeway environments to capture any potential differences in driver responses based on the demands of the environment. For example, freeway drivers are expected to primarily respond to interactions with other vehicles, while drivers in urban environments should also respond to interactions with bicyclists and pedestrians, vehicles entering and exiting driveways, and other vehicles at intersections. Reaction times then should have distinctly different distributions at each of these types of locations. Finally, longer median reaction times were expected among the older drivers in the sample. Driver age was initially categorized using the five-year increments defined in the NDS database, but the initial statistical model results indicated that reaction times were relatively consistent across all age groups except for teen drivers (age 16-19). Subsequent models divided driver age into "Teens" and "Older than 19." Table 1 summarizes how the incidents from the 
selected data set were distributed across the model variables, and Table 2 summarizes the average reaction time, in milliseconds, from the dataset distributed across the model variables. As the two tables show, for most combinations of the critical variables, data was scarce, which limited the number of variable interactions that could be modeled.

Table 1. Frequency of Incidents Across Age, Distraction Type, and Roadway Location.

\begin{tabular}{|c|c|c|c|c|c|c|c|c|}
\hline & & & & & \multirow{2}{*}{\multicolumn{3}{|c|}{ No Crash }} & \multirow{3}{*}{ Totals } \\
\hline \multirow{2}{*}{$\begin{array}{l}\text { Age } \\
\text { Group }\end{array}$} & \multirow[t]{2}{*}{ Distraction Type } & \multicolumn{3}{|c|}{ Crash } & & & & \\
\hline & & Fwy & Residential & Urban & Fwy & Residential & Urban & \\
\hline \multirow[t]{3}{*}{ Teens } & None/Baseline & 0 & 1 & 0 & 8 & 8 & 9 & 26 \\
\hline & Manual-Cognitive & 0 & 0 & 2 & 2 & 0 & 5 & 9 \\
\hline & Visual-Manual & 0 & 1 & 4 & 2 & 3 & 4 & 14 \\
\hline \multirow{3}{*}{$\begin{array}{l}\text { Older } \\
\text { than } 19\end{array}$} & None/Baseline & 1 & 2 & 4 & 49 & 14 & 52 & 122 \\
\hline & Manual-Cognitive & 0 & 0 & 0 & 11 & 4 & 12 & 27 \\
\hline & Visual-Manual & 1 & 1 & 5 & 18 & 3 & 23 & 51 \\
\hline Totals & & 2 & 5 & 15 & 90 & 32 & 105 & 249 \\
\hline
\end{tabular}

Table 2. Median Reaction Times Across Age, Distraction Type, and Roadway Location.

\begin{tabular}{|c|c|c|c|c|c|c|c|}
\hline \multirow{2}{*}{$\begin{array}{l}\text { Age } \\
\text { Group }\end{array}$} & \multirow[t]{2}{*}{ Distraction Type } & \multicolumn{3}{|c|}{ Crash } & \multicolumn{3}{|c|}{ No Crash } \\
\hline & & Fwy & Residential & Urban & Fwy & Residential & Urban \\
\hline \multirow[t]{3}{*}{+ Teens } & None/Baseline & N.A. & $1,924.0$ & N.A. & 640.5 & 991.0 & 707.0 \\
\hline & $\begin{array}{l}\text { Manual- } \\
\text { Cognitive }\end{array}$ & N.A. & N.A. & $2,228.5$ & 832.5 & N.A. & 872.0 \\
\hline & Visual-Manual & N.A. & $3,432.0$ & $2,368.0$ & 749.0 & $1,626.0$ & $2,582.0$ \\
\hline \multirow{3}{*}{$\begin{array}{l}\text { Older } \\
\text { than } 19\end{array}$} & None/Baseline & $1,950.0$ & 620.0 & 1960.5 & $1,471.0$ & $1,506.0$ & $1,480.0$ \\
\hline & $\begin{array}{l}\text { Manual- } \\
\text { Cognitive }\end{array}$ & N.A. & N.A. & N.A. & $2,031.0$ & $1,756.0$ & $2,046.5$ \\
\hline & Visual-Manual & $4,168.0$ & $3,514.0$ & $2,942.0$ & $2,175.0$ & 405.0 & $2,085.0$ \\
\hline \multicolumn{8}{|c|}{ Overall RT distribution statistics: } \\
\hline Minimur & $17.5 \mathrm{~ms}$ & & & Mean: & $2,142 \mathrm{~ms}$ & & \\
\hline $1^{\text {st }}$ Quan & $864 \mathrm{~ms}$ & & & $3^{\text {rd }}$ Quartile: & $2,810 \mathrm{~ms}$ & & \\
\hline Median: & $1,790 \mathrm{~ms}$ & & & Maximum: & $12,213 \mathrm{~ms}$ & & \\
\hline
\end{tabular}

\section{RESULTS}

The NDS data was used in two separate analyses: one examining the effects of age, distraction type, and location on reaction times (RT), and one examining their effects on the odds of crash involvement. The effects of these three variables, as described in the following results sections, are after controlling for individual effects among individuals, as the mixed-effects model included a random effect per driver.

\section{Reaction Time Analysis}

The first analysis compared driver reaction times to precipitating events across driver age groups, event locations, and cell phone use types (including no cell phone use). Reaction time was defined as the difference between the start of a precipitating event (e.g., a braking lead vehicle) and the start of the driver's first recognizable reaction to the precipitating event as coded by VTTI data reductionists. Preliminary examination of RT as a response variable indicated positive skewness. To account for this feature, the research team used a log-transformation on this variable before the analysis, which shifts the focus of the analysis from the mean RT to the median RT. The research team verified that the normality assumption of model residuals was 
met after carrying the transformation. Table 3 shows the most parsimonious functional form, after model selection.

Effect of Distraction Type. The results indicate that, after accounting for other influential variables in cases where a critical event occurs, median RT is $40.5 \%$ longer among drivers who are engaged in visual-manual distractions $(1.405=\exp [0.34])$. The difference in median RT between manual-cognitive distracted and non-distracted drivers was found not statistically different from zero.

Effect of Urban Environments. After accounting for other influential variables, this analysis found that crash or near-crash events in urban environments were associated with a median RT 1.377 times larger than events in highway or residential environments $(1.377=\exp [0.32])$. Effect of Age. After accounting for other influential variables, this analysis found that teen drivers involved in crash or near-crash events had faster reaction times than older drivers. The median RT for teens was found to be 0.733 times the median RT of their older counterparts $(0.733=\exp [-0.31])$.

Table 3. Linear Mixed-effects Model Coefficients on Ln(RT) $(n=249)$

\begin{tabular}{|c|c|c|c|c|c|c|c|}
\hline Variable & Estimate & Std. Error & df & t value & $p$ value & Significance & $\begin{array}{c}\text { Effect } \\
\text { size }^{\mathrm{d}}\end{array}$ \\
\hline Intercept $\mathrm{t}^{\mathrm{a}}$ & 7.12 & 0.13 & 12.59 & 56.00 & $2.22 \mathrm{E}-16$ & $* * *$ & N.A. \\
\hline Manual-Cognitive & 0.13 & 0.18 & 239.76 & 0.71 & $4.78 \mathrm{E}-01$ & & $+172 \mathrm{~ms}$ \\
\hline Visual-Manual & 0.34 & 0.14 & 239.99 & 2.45 & $1.52 \mathrm{E}-02$ & $*$ & $+501 \mathrm{~ms}$ \\
\hline $\begin{array}{l}\text { Precip. Event by } \\
\text { Subject Vehicle }\end{array}$ & 0.38 & 0.20 & 239.23 & 1.89 & $5.99 \mathrm{E}-02$ & $\sim$ & $+572 \mathrm{~ms}$ \\
\hline Urban & 0.32 & 0.12 & 241.21 & 2.59 & $1.03 \mathrm{E}-02$ & $*$ & $+466 \mathrm{~ms}$ \\
\hline Teens & -0.31 & 0.15 & 242.52 & -2.03 & 4.39E-02 & $*$ & $-330 \mathrm{~ms}$ \\
\hline $\begin{array}{l}\text { Participant } \text { ID }^{\mathrm{b}} \\
\text { Traffic Density }^{\mathrm{b}} \\
\text { Residual }^{\mathrm{c}}\end{array}$ & \multicolumn{7}{|c|}{$\begin{array}{c}<0.0001(182) \\
0.0281(7) \\
0.8821\end{array}$} \\
\hline
\end{tabular}

Notes:

Significant level thresholds are defined as follows: $\mathrm{p}<0.1 \sim$; $<0.05 * ; \mathrm{p}<.01 * * ; \mathrm{p}<.001 * * *$.

${ }^{a}$ The reference level for this analysis is non-distracted drivers of 19 or more years of age at freeway/highway or residential environments, that responded to precipitating events initiated by a different vehicle. Coefficients represent shifts in the log-transformed RT corresponding to marginal variations from the reference level.

${ }^{\mathrm{b}}$ Random effects variance, number of levels is shown in parenthesis.

${ }^{\mathrm{c}}$ Residual Variance (in log-scale)

${ }^{d}$ The difference in reaction time, in ms, for a driver when each factor is true, compared to a driver in the reference level of the analysis.

\section{Crash Probability Analysis}

Similar to the RT analysis, the research team analyzed crash probability as a function of distraction and other potential explanatory variables. The tool selected for this analysis was a Generalized Linear Mixed Model with a logistic link function. Model selection was carried over the initial set of variables using the Akaike Information Criterion to balance parsimony and model fit. Table 4 shows the most parsimonious functional form, after model selection. Effect of Distraction Type. The results indicate that, after accounting for other influential variables and given that a critical event occurs, the odds of a crash among drivers who were engaged in visual-manual distractions were 4.7 times the odds of a crash outcome among drivers 
who were not distracted. The odds ratio between manual-cognitive distracted and non-distracted drivers was found not statistically different from 1.0.

Effect of Urban Environments. After accounting for other influential variables, this analysis found that the odds of a crash outcome in urban environments (given a precipitating event) were 3.4 times as large as for events in highway or residential environments.

Effect of Age. Contrary to the findings in the RT analysis, teens were found to be more likely to be involved in crashes than their older counterparts, other things equal and given that a precipitating event occurs. This analysis found that the odds of teen-driver events resulting in crashes were 8.2 times as large as the odds of their older counterparts.

Table 4. Linear Mixed-effects Model Coefficients on P(Crash) $(n=249)$

\begin{tabular}{|c|c|c|c|c|c|}
\hline \multicolumn{2}{|c|}{ 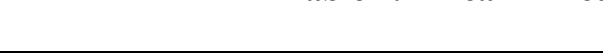 } & \multicolumn{2}{|c|}{ 95\% Confidence Interval } & \\
\hline & $\begin{array}{c}\text { O.R. } \\
\text { (Point } \\
\text { Estimate) }\end{array}$ & $\begin{array}{c}\text { O.R. } \\
\text { Low } \\
\text { Limit }\end{array}$ & $\begin{array}{c}\text { O.R. } \\
\text { High } \\
\text { Limit }\end{array}$ & p value & Significance \\
\hline Manual-Cognitive & 0.9 & 0.2 & 5.1 & $8.98 \mathrm{E}-01$ & \\
\hline Visual-Manual & 4.7 & 1.7 & 13.2 & $3.63 \mathrm{E}-03$ & $* *$ \\
\hline $\begin{array}{l}\text { Precip. Event by } \\
\text { Subject Vehicle }\end{array}$ & 3.1 & 1.1 & 8.7 & $3.27 \mathrm{E}-02$ & * \\
\hline Urban & 3.4 & 1.2 & 9.8 & 2.32E-02 & $*$ \\
\hline Teens & 8.2 & 2.4 & 27.5 & $7.28 \mathrm{E}-04$ & $* * *$ \\
\hline $\begin{array}{l}\text { Notes: } \\
\text { Significant level thr } \\
\text { a The reference leve } \\
\text { or residential enviro } \\
\text { represent shifts in th } \\
\text { level. } \\
\text { b } \\
{ }^{2} \text { Random effect var }\end{array}$ & $\begin{array}{l}\text { are defined } \\
\text { analysis is } \\
\text { that respon } \\
\text { dds of a cras } \\
\text { n link scale). }\end{array}$ & $\begin{array}{l}\text { lows: } \mathrm{p}<0 \text {. } \\
\text { listracted d } \\
\text { precipitati } \\
\text { come corre }\end{array}$ & $\begin{array}{l}; p<0.05 * ; p \\
\text { ers of } 19 \text { or } m \\
\text { events initiat } \\
\text { onding to mar }\end{array}$ & $\begin{array}{l}<.01 * * ; \mathrm{p}<.00 \\
\text { hore years of age } \\
\text { ted by a different } \\
\text { ginal variations } t\end{array}$ & $\begin{array}{l}\text { eway/highway } \\
\text { le. Coefficients } \\
\text { e reference }\end{array}$ \\
\hline
\end{tabular}

\section{Relationship between Reaction Time and Probability of Crashes}

This research modeled both reaction time and probability of crash as response variables dependent on, among other variables, the type of distraction in which drivers were engaged. The research team fitted a LOESS non-parametric regression trend. This is a type of local regression. The principle behind this procedure is to fit local models to subsets of data in order to describe the deterministic part of the variation in the data, point by point. Figure 1 shows how the fitted values from both analyses relate to each other, by distraction type. It should be noted that, given the limited number of levels of the independent variables, there are only 63 different values of predicted RT; similarly, due to the small number of crashes, there are only 18 different predicted crash probabilities for the 249 events included in this study. As a result, Figure 1 shows far fewer than 249 different data points, though all 249 events were included in the analysis.

It is clear that higher reaction times are associated with higher probabilities of a crash. The probability of a crash is flat and relatively low at reaction times of $1500 \mathrm{~ms}$ or less, and it begins to climb as reaction times go up. The trends for non-distracted and manual-cognitive distracted drivers (e.g., those holding a cell phone and talking) appear very close to each other and below the trend for visual-manually distracted drivers (e.g., those who are texting) in the flat region of the plot. The three trends come close together and behave similarly in the steep part of the plot. 


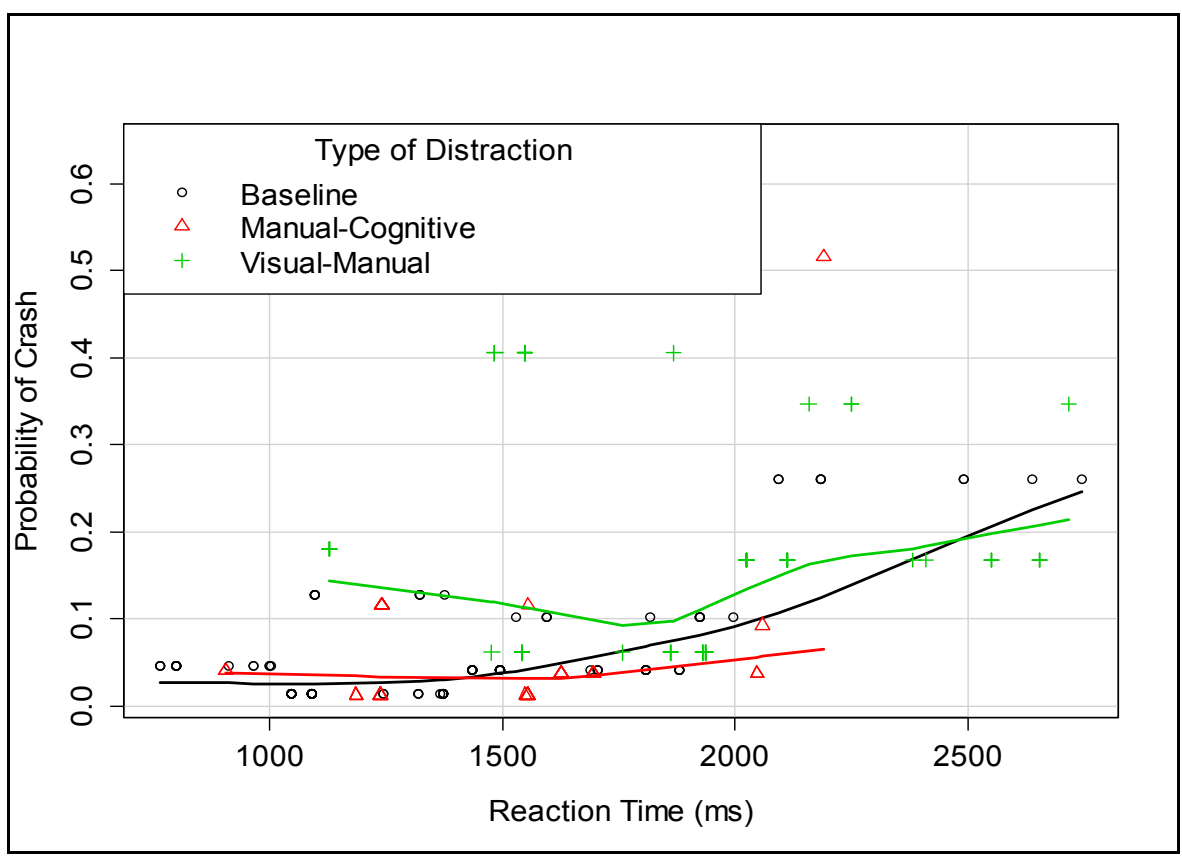

Figure 1: Empirical Relationship between Probability of Crash vs. Expected Reaction Time.

\section{CONCLUSIONS}

This analysis of naturalistic driving data found results that support many earlier drivingsimulator and test-track studies of the effects of texting and driving. Median reaction times were $40.5 \%$ higher among drivers who were using their phones to text or to perform other visualmanual tasks, and crash risk was 4.66 higher for these drivers compared to undistracted drivers. While several prior studies have found that talking on a cell phone while driving is detrimental to driver attention and reaction time (Caird et al, 2008), no significant change in reaction time or crash risk was found from the data examined in this study. One potential explanation is that, in naturalistic driving, drivers have the ability to control when and where they choose to talk or text. The increased risk shown for texting drivers in the SHRP2 NDS data may indicate that, even when drivers can choose when to read and write texts, the visual attention required can delay or prevent them from noticing when the roadway situation changes. Increased reaction times and crash risk for urban environments (as compared to freeway/highway or residential) may be due to the increased visual complexity and more frequent conflict points found in an urban traffic environment. Finally, across all driver behavior categories (distracted and undistracted), young drivers (age 16-19) exhibited faster reaction times to precipitating events than their older counterparts but were more likely to be involved in a crash. Lack of driving experience is a likely reason for this increased crash risk; teen drivers may be more likely than older drivers to execute an ineffective or incomplete evasive maneuver in response to a precipitating event.

The study also demonstrates the value of using the SHRP2 dataset's coded variables without additional individual research team review of the driver face videos. While the videos provide valuable data about distracted driving behaviors, including eyes-off-road time, the pre-coded variables alone provide substantial information about the effects of various types of distraction 
on driver performance. A limitation of the study was the relatively small sample size, which limited statistical power to detect more nuanced relationships (e.g., some interactions of variables of interest).

\section{ACKNOWLEDGMENTS}

The authors would like to acknowledge the assistance of Bahar Dadashova in obtaining the NDS data that was used for this analysis, and Nikita Eswar for her assistance in reducing the data. This analysis was funded by the Strategic Research Program at the Texas A\&M Transportation Institute.

\section{REFERENCES}

Caird, J.K., Willness, C.R., Steel, P., and Scialfa, C. (2008). "A meta-analysis of the effects of cell phones on driver performance", Accident Analysis and Prevention, 40, 2008, pp. 12821293.

Caird, J.K., Johnston, K.A., Willness, C.R., Asbridge, M., Steel, P. (2014) "A meta-analysis of the effects of texting on driving." Accident Analysis and Prevention, Vol. 71, 311-318.

Carney, C., McGehee, D., Harland, K., Weiss, M., and Raby, M. (2016) Using Naturalistic Driving Data to Examine Teen Driver Behaviors Present in Motor Vehicle Crashes, $2007-$ 2015. AAA Foundation for Traffic Safety, Washington D.C.

Cooper, J., Yager, C. and Chrysler, S. (2011) "An Investigation of the Effects of Reading and Writing Text-Based Messages while Driving," Southwest Region University Transportation Center, College Station, TX.

Dingus, T., Guo, F., Lee, S., Antin, J., Perez, M., Buchanan-King, M. and Hankey, J. (2016) "Driver Crash Risk Factors and Prevalence Evaluation Using Naturalistic Driving Data," Procedures of the National Academy of Science, 1-6.

Funkhauser, D., Sayer, J. Naturalistic census of cell phone use. (2012) Transportation Research Record 2321, 1-6.

Klauer, S.G., Dingus, T.A., Neale, V.L., Sudweeks, J.D., and Ramsey, D.J. (2006) The Impact of Driver Inattention on Near-Crash/Crash Risk: An Analysis Using the 100-Car Naturalistic Driving Study Data. DOT HS 810 594, USDOT/National Highway Traffic Safety Administration, Washington, D.C.

Strayer, D.L., Drew, F.A. (2004) Profiles in Driver Distraction: Effects of Cell Phone Conversations on Younger and Older Drivers. Human Factors Vol. 46 No. 4, pp.640-649.

Tivesten, E. Dozza, M. (2014) Driving context and visual-manual phone tasks influence glance behavior in naturalistic driving. Transportation Research Part F: Traffic Psychology and Behaviour, 26 Part A(0), 258-272.

Tivesten, E. and Dozza, M. (2015) Driving context influences drivers' decision to engage in visual-manual phone tasks: Evidence from a naturalistic driving study. Journal of Safety Research 53, 87-96. 